\title{
Apontamentos sobre as ausências da Base Nacional Comum Curricular de Matemática
}

\author{
Júlio César Augusto do Valle
}

\begin{abstract}
Resumo: Este texto sistematiza resultados oriundos da pesquisa sobre a formulação da Base Nacional Comum Curricular (BNCC), com ênfase em seu conteúdo relativo à matemática. A partir do repertório teóricometodológico-epistemológico da Sociologia das Ausências e das Emergências, com respaldo da análise documental e da revisão bibliográfica, objetiva-se identificar ausências atinentes ao documento, tanto nos termos da política curricular estabelecida, como também seus desdobramentos curriculares para a Matemática escolar. $O$ estudo, sem pretensão de esgotar as investigações sobre a temática, permite sinalizar ao menos três ausências endereçadas à reflexão sobre currículo e suas políticas: a ausência da autoria docente, em particular de quem ensina matemática; a ausência da pluralidade de concepções pedagógicas e a ausência das perspectivas socioculturais da Educação Matemática.
\end{abstract}

Palavras-chave: Currículo. Política curricular. BNCC. Educação Matemática. Sociologia das Ausências e das Emergências.

\section{Notes on the absences of the National Common Curricular Base of Mathematics}

Júlio César Augusto do Valle Doutor em Educação pela Universidade de São Paulo (USP). Professor do Instituto de Matemática e Estatística da USP. São Paulo, São Paulo, Brasil.

(D) https://orcid.org/0000-0002-7971-

$\underline{0405}$

$\bowtie$ juliio.valle@gmail.com

Recebido em 19/04/2021

Aceito em 19/06/2021

Publicado em 26/07/2021

\begin{abstract}
This text systematizes results from research on the formulation of the National Common Curricular Base, with an emphasis on its content related to mathematics. Based on the theoretical-methodological-epistemological repertoire of Sociology of Absences and Emergencies, supported by documentary analysis and bibliographic review, the objective is to identify absences related to the document, both in terms of the established curricular policy, as well as its curricular developments for school mathematics. The study, without pretending to exhaust investigations on the theme, allows us to signal at least three absences addressed to the reflection on curriculum and its policies: the absence of teaching authorship, particularly of those who teach mathematics; the absence of the plurality of pedagogical conceptions and the absence of the socio-cultural perspectives of Mathematics Education.
\end{abstract}

Keywords: Curriculum. Curriculum policy. BNCC. Mathematics education. Sociology of Absences and Emergencies.

\section{Notas sobre las ausencias de la Base Curricular Común Nacional de Matemáticas}

Resumen: Este texto sistematiza resultados de investigaciones sobre la formulación de la Base Curricular Común Nacional, con énfasis en su contenido relacionado con las matemáticas. A partir del repertorio teórico-metodológico-epistemológico de la Sociología de las Ausencias y Emergencias, sustentado en el análisis documental y revisión bibliográfica, el objetivo es identificar las ausencias relacionadas con el documento, tanto en términos de la política curricular establecida, como de su plan de estudios. desarrollos para las matemáticas escolares. El estudio, sin pretender agotar las investigaciones sobre el tema, permite señalar al menos tres ausencias dirigidas a la reflexión sobre el currículo y sus políticas: la ausencia de autoría docente, particularmente de quienes enseñan matemáticas; la ausencia de la pluralidad de concepciones pedagógicas y la ausencia de las perspectivas socioculturales de la Educación Matemática. 


\section{revemop}

Palabras clave: Currículo. Política curricular. BNCC. Educación Matemática. Sociología de Ausencias y Emergencias.

\section{Introdução1}

Cury, Reis \& Zanardi (2018, p. 130) encerram sua análise sobre a Base Nacional Comum Curricular (BNCC) afirmando que: "desvelar a BNCC se constitui em obrigação dos educadores para compreensão dos projetos que se colocam em disputa na sociedade e no interior da escola". Conforme outros trabalhos têm discutido, a Base Nacional Comum Curricular (BNCC), enquanto política curricular nacional, se constitui como resultado de um processo cujo caráter tem sido identificado como antidemocrático, porque desconsiderou as contribuições críticas de diferentes setores da sociedade (DOURADO \& AGUIAR, 2018; CÁSSIO \& CATELLI, 2019).

Em particular, como identificado em Valle (2020), foram negligenciados os apontamentos feitos por pesquisadoras e pesquisadores das universidades e associações educacionais, tais como a Sociedade Brasileira de Educação Matemática (SBEM), que coassinou diferentes ofícios encaminhados aos seus elaboradores e representantes no Ministério da Educação pela Associação Nacional de Pós-graduação e Pesquisa em Educação (ANPEd) e Associação Brasileira de Currículo (ABdC).

Aguiar (2018, p. 14), membro do Conselho Nacional de Educação (CNE) à época da elaboração da BNCC, denuncia a celeridade com que o processo tramitou e que impediu a avaliação rigorosa que essa elaboração demanda, em especial se consideramos seus efeitos para a formação de professores, produção de materiais didáticos e avaliação em geral. Por esses e outros motivos, alguns evidenciados no decorrer do texto, as diferentes perspectivas expressas em Dourado \& Aguiar (2018) convergem para a denúncia de que a BNCC que temos está na contramão do Plano Nacional de Educação (PNE, 2014-2024). Produto de decisões questionáveis e desconectadas de movimentos de efetiva escuta e participação dos educadores e das educadoras de todo o país, como descrito em textos anteriores (VALLE \& MORAIS, 2019; VALLE, 2020), a BNCC tem gerado intensos debates no campo do currículo e também dos currículos de matemática (PINTO, 2017; BIGODE, 2019).

Inserimo-nos neste território de intensos debates sobre a política curricular nacional, para refletir, em particular,sobre como a matemática escolar tem sido concebida e apresentada nesse contexto de proposição curricular. As críticas realizadas por pesquisadres/as do campo do

1 Este trabalho constitui o registro sistematizado de resultados obtidos a partir da pesquisa apresentada na $14^{\text {a }}$ Reunião Científica Regional da Associação Nacional de Pós-Graduação e Pesquisa em Educação (ANPEd), realizada em Dezembro de 2020. 
currículo sobre a BNCC têm sinalizado lacunas do próprio texto e de seu processo de elaboração como proposta curricular. Nesse mesmo sentido, indagamo-nos sobre quais são as lacunas da BNCC, no que se refere à Matemática? Neste artigo, reunimos e discutimos, então, algumas respostas a essa questão que compreendemos como capazes de subsidiar uma leitura crítica sobre a Base Nacional Comum Curricular de Matemática, que se faz indispensável à formação e atuação docente, conforme o excerto com que introduzimos o texto.

\section{Fundamentação e orientação metodológica}

Orientamo-nos pela Sociologia das Ausências e das Emergências de Boaventura de Sousa Santos (2020, p. 28), compreendendo "que muito do que não existe em nossa realidade é produzido ativamente como não existente, e por isso a armadilha maior para nós é reduzir a realidade ao que existe". Posicionando-nos em diametral oposição às ausências construídas, representantes dessa "racionalidade preguiçosa, que realmente produz como ausente muita realidade que poderia estar presente" (SANTOS, 2007, p. 20), dedicamo-nos à crítica do modo como as políticas curriculares oficiais têm sistematicamente invisibilizado, construindo como ausentes, os currículos pensadospraticados (OLIVEIRA, 2013), propostas curriculares que lograram êxito respeitando a autonomia docente e das escolas, as práticas cotidianas emancipatórias.

As experiências cotidianas complexas e diversas da Educação Básica no Brasil, desconsideradas, acabam "desperdiçadas", para utilizar a expressão de Santos (2007, p. 28), pelas políticas curriculares incapazes de reconhecê-las, de considerá-las ou mesmo de interagir com elas fora do âmbito da prescrição, verticalizada. Não porque não se possa construir propostas curriculares como política pública, mas porque fazê-lo desconsiderando tais experiências reforça os estereótipos de quem pensa o currículo e de quem o executa (SILVA, 2011; LOPES \& MACEDO, 2011). Nesse sentido, o exercício a que nos dedicamos, orientados pela Sociologia das Ausências e das Emergências (SANTOS, 2007), que nos remete à "epistemologia dos agentes ausentes" (SANTOS, 2002, p. 249), consiste em identificar as ausências na construção desta política curricular em particular, a BNCC, com ênfase dada à parte de matemática.

Trata-se de identificar as ausências desta política curricular como produções ativas de sentidos, significados e existências em termos do que se assume como referencial para políticas de formação de professores, de produção e distribuição de livros/materiais didáticos e paradidáticos, políticas de avaliação, remetendo-nos, inclusive, neste caso, à questão do que se 
define como qualidade da Educação Básica (DOURADO \& AGUIAR, 2018; DOURADO \& SIQUEIRA, 2019). Compreender que o ausente é produzido ativamente como ausente significa, conforme assumimos, que "o que não existe é produzido ativamente como não existente, como uma alternativa não crível, como uma alternativa descartável, invisível à realidade hegemônica do mundo" (SANTOS, 2007, p. 28). No caso da autoria docente nos processos de elaboração curricular, por exemplo, descartar a experiência do trabalho docente e os saberes decorrentes dessas experiências contribui para a desprofissionalização e precarização da docência.

Valemo-nos também da análise documental, conforme apresentado em trabalho anterior (VALLE, 2020), mobilizando-a não somente para leitura dos principais documentos elaborados no decorrer da elaboração da BNCC, mas, em especial, para o estudo das notas e ofícios encaminhados pelas principais associações científicas da educação no Brasil no mesmo período. Sob a perspectiva de assinalar as ausências, tais documentos expressavam preocupações compreendidas "além de legítimas, como subsidiárias e representativas das perspectivas ignoradas tanto pelo Ministério da Educação como também pelo Conselho Nacional de Educação, com ênfase no período de 2015 a 2018" (VALLE, 2020, p. 921).

Os principais documentos considerados foram:

- Ofício n. 01/2015/GR - Exposição de motivos sobre a Base Nacional Comum Curricular (ANPEd \& ABdC, 2015);

- Ofício n. 138/2015 - A Associação Nacional de Pós-Graduação e Pesquisa em Educação e a Base Nacional Comum Curricular (ANPEd, 2015)

- Ofício n. 31/2016 - Aos deputados da Comissão de Educação da Câmara dos Deputados (ANPEd, 2016);

- Nota sobre a entrega da terceira versão da Base Nacional Comum (ANPEd, 2017a);

- Ofício de "Solicitação de respostas às notas das entidades educacionais" ao Conselho Nacional de Educação (CNE), coassinado pelas entidades ANFOPE, ANPAE, ABdC, CEDES e FORUMDIR² (ANPEd, 2017b)

- Nota "A proposta da BNCC do Ensino Médio: alguns pontos para o debate" (ANPEd, 2018);

- Nota sobre processos de implantação da Base Nacional Comum Curricular do Ensino Fundamental (ABdC, 2018). (VALLE, 2020, p. 922)

Com a orientação metodológica da análise documental dedicamo-nos, a partir da definição deste corpus, a "identificar informações factuais nos documentos a partir de questões e hipóteses de interesse" (LÜDKE \& ANDRÉ, 1986, p. 38)3. Para as finalidades deste artigo,

2 Além das já mencionadas anteriormente, as demais entidades são: ANFOPE - Associação Nacional pela Formação dos Profissionais da Educação; CEDES - Centro de Estudos Educação e Sociedade FORUMDIR - Fórum Nacional de Diretores de Faculdades, Centros de Educação e Equivalentes das Universidades Públicas Brasileiras. $3 \quad$ Para uma leitura mais detalhada sobre a análise feita a partir dos documentos mencionados, recomendamos Valle (2020). Além disso, tais documentos podem ser lidos, na íntegra, nos sites das respectivas associações científicas. 
identificamos, nos documentos mencionados, como se deu a interação entre os responsáveis, no Ministério da Educação, pela elaboração da BNCC e as associações científicas da Educação, por meio dos posicionamentos explicitados nos referidos ofícios e notas.

Ademais, recorremos à revisão bibliográfica da produção científica no campo dos currículos, com ênfase dada à produção oriunda das investigações sobre currículos de matemática, assim como sobre a formulação e o conteúdo da política curricular em foco, a BNCC.Sobre estas últimas, identificamos as primeiras publicações dedicadas a explorar e analisar criticamente o processo de elaboração curricular da BNCC: Dourado \& Aguiar (2018)4 , Cury, Reis \& Zanardi (2018) e Cássio \& Catelli (2019). A partir destas mapeamos outras publicações de seus/suas autores/as.

Em relação à produção oriunda das investigações sobre currículos de matemática, valemo-nos das perspectivas expressas por Fiorentini (1995), Gottschalk (2002), Pires (2005; 2008), Pires \& Silva (2011), Palanch (2016) e Bigode (2019), que nos informam, sob diferentes perspectivas, sobre 0 estado dos currículos de matemática desde 0 contexto das reformas educacionais brasileiras da primeira metade do século passado até o contexto da Base Nacional Comum Curricular (BRASIL, 2017). Buscando mapear publicações dedicadas à reflexão sobre a BNCC de Matemática, em particular, identificamos também Pinto (2017), Santos (2018) e Malheiros \& Forner (2020), como publicações recentes em periódicos da área, além de Bigode (2019), conforme já mencionado. Valemo-nos das contribuições de Oliveira (2013), que nos informa sobre modos de compreender os currículos pensadospraticados a partir da invisibilidade que Ihes é atribuída pelos processos de prescrição curricular, além de D'Ambrosio (2020), que nos informa sobre o caráter sociocultural da matemática, como constructo humano, a partir da etnomatemática.

\section{Contexto e dilemas da Base Nacional Comum Curricular}

Dentre os trabalhos que se dedicam a compreender o contexto e os dilemas relacionados à construção da BNCC, a revisão bibliográfica nos permitiu identificar e dialogar com os trabalhos de Oliveira \& Süssekind (2018), Cury, Reis \& Zanardi (2018), Cássio \& Catelli Jr. (2019), Dourado \& Aguiar (2018), Dourado \& Siqueira (2019), e Arelaro, Peroni \& Caetano (2019). Sob diferentes

4 Vale observar que esta referência, citada desde a introdução, constitui também a perspectiva de pesquisadores/as da Associação Nacional de Pesquisa em Administração Escolar (ANPAE) e, portanto, outra associação científica da Educação. 


\section{revemop}

perspectivas, inclusive históricas, sobre o processo de elaboração da BNCC, esses trabalhos sinalizam, conforme veremos, preocupações relevantes sobre a política curricular ensejada pela Base.

Primeiro, pela compreensão, criticada por Arelaro, Peroni \& Caetano (2019), de que a BNCC responderia à demanda constitucional contida no Art. 210: "Serão fixados conteúdos mínimos para o ensino fundamental, de maneira a assegurar formação básica comum e respeito aos valores culturais e artísticos, nacionais e regionais" (BRASIL, CF, 1988). Existe, segundo as autoras, uma compreensão divergente, segundo a qual as Diretrizes Curriculares Nacionais (DCN) teriam contemplado essa demanda 5 . A própria disputa em torno da nomenclatura da política evidencia a divergência dessas compreensões: "base comum nacional", conforme entendiam as associações científicas, ao invés de "base nacional comum curricular", por compreender que 0 nome expressa uma síntese da concepção subjacente à política.

Segundo, pelo fato evidenciado por Oliveira (2018), de que a atenção sobre as metas e estratégias do Plano Nacional de Educação (PNE, 2014-2024) foi distribuída de modo desigual, provocando distintas assimetrias em sua efetivação. Para a autora, é flagrante a divergência de esforços empreendidos para o alcance das distintas metas que constituem o PNE. A sétima meta do PNE, cujas estratégias foram mobilizadas como argumento em favor da BNCC, recebeu, sob a perspectiva enunciada, mais atenção do que, por exemplo, as metas relacionadas à Educação de Jovens e Adultos, que pouco avançaram em relação ao cenário identificado em 2014. "Entre outros problemas e equívocos", destaca Oliveira (2018, p. 56), "a meta 7 do PNE reduz a compreensão da melhoria do ensino à melhoria do IDEB das escolas, quantificando resultados a partir de graus em provas e índices de permanência e aprovação escolar".

Terceiro, pela negligência com os posicionamentos das associações científicas de que tratamos durante todo o processo de elaboração da política curricular nacional, fato este que nos chamou a atenção para a necessidade de incluir suas manifestações, ofícios e notas, como parte do corpus de análise. Para Cury, Reis \& Zanardi (2018, p. 95), "o caso da BNCC e as associações de pesquisas acadêmicas é um capítulo à parte no seu desenrolar" porque, conforme argumentam

5 Em um dos documentos elaborados pela ANFOPE, lemos que: "A BNCC em nada se assemelha a base comum nacional gestada, coletivamente, em meio a luta democrática de profissionais da educação pela participação nas discussões acerca das propostas de formação de professores no contexto de redemocratização no Brasil, na década de 1980. A base comum nacional, que defendemos historicamente e que está contemplada nas Diretrizes Curriculares Nacionais para a Formação para a Formação Inicial e Continuada de Professores (Resolução CNE Nº2/2015), é uma concepção básica de formação do educador e um corpo de conhecimento fundamental em que a docência se constitui como a base da identidade profissional de todo educador, e, portanto, não pode ser confundida como um currículo mínimo ou um elenco de disciplinas" (ANFOPE, 2018, p. 2) 
os autores, "as associações, especialmente, da Associação Nacional de Pesquisa em Educação (ANPEd), sempre canalizaram críticas não só ao conteúdo da BNCC, mas à metodologia e à própria concepção de currículo nacional que a BNCC incorpora".

Quarto, pelas alterações impostas ao processo desde sua retomada, em 2014, ainda sob a gestão de um governo democraticamente eleito, até sua conclusão, em 2017, sob a condução de outro governo, que imprimiu outras marcas ao documento. Este ponto é importante porque havia uma expectativa de que o governo anterior, de Dilma Rousseff, privilegiasse as condições de participação democrática para construção da política (OLIVEIRA \& SÜSSEKIND, 2018, p. 56). Ao invés disso, "a ruptura institucional e democrática, ocorrida em 2016, deixa marcas indeléveis nas políticas públicas brasileiras", como afirmam Cury, Reis e Zanardi (2018, p. 77-78), de modo que se privilegiam "políticas públicas alinhadas com os interesses do capital frente ao sistema educacional público brasileiro [...] [e] a BNCC se situa nesse contexto de medidas e soluções para superação da crise".

Em especial a partir desse último aspecto, tecemos adiante algumas considerações que nos permitem compreender como tais preocupações, sinalizadas nos trabalhos mencionados, se materializaram no processo de elaboração da BNCC. Para essa abordagem, remetemo-nos à inflexão realizada na retomada da elaboração da BNCC pós-golpe, contexto em que:

\begin{abstract}
O Professor Manuel Palácios assumiu a SEB e montou uma equipe de "especialistas" para a elaboração da BNCC, apoiado em um discurso de que a BNCC estaria sendo democraticamente formulada por contar com professores de todos os níveis de ensino e de todas as regiões do país. (...) a "democraticidade" do conjunto escondia uma fragilidade real de equipes pequenas, trabalhando isoladamente, apenas em torno dos conteúdos de suas respectivas disciplinas. Chamávamos a atenção para o fato de que o debate curricular não estava sendo feito nas escolas, nem com as escolas. (OLIVEIRA \& SÜSSEKIND, 2018, p. 57)
\end{abstract}

Essa expectativa de que uma pequena comunidade de especialistas pudesse redigir 0 texto que busca identificar o que é comum e nacional no Brasil, para Cury, Reis \& Zanardi (2018, p. 87), "é tributária de um currículo que desconfia do potencial transformador que o contexto vivido, do diálogo e da problematização como princípios orientadores da construção curricular".

Os especialistas, mencionados antes, elaboraram a primeira versão do documento, que foi colocada em consulta pública, por meio de internet, entre outubro de 2015 e março de 2016. Segundo dados do MEC6, houve mais de 12 milhões de contribuições ao texto, que contou, 


\title{
revemop
}

também, com pareceres de especialistas, associações científicas e membros da comunidade acadêmica (AGUIAR, 2018). Porém, conforme lemos em Cássio (2019, p. 27):

\begin{abstract}
Desde 2016, o discurso laudatório da BNCC tem se apoiado em uma série de dados que comprovariam as virtudes democráticas do processo de construção da Base, começando pelas incríveis "12 milhões de contribuições" provenientes da consulta pública à primeira versão. [...] A análise dos microdados da consulta pública, obtidos via Lei de Acesso à Informação (Lei n. 12.527/2011), mostra que o número total de contribuintes únicos da consulta é 143.928. Logo, entre o número de contribuintes únicos e as 12 milhões de "contribuições" divulgadas há uma diferença de $8400 \%$. Para o MEC, um clique de "concordo" e um comentário crítico com 50 linhas foram igualmente considerados "contribuições". Por isso, 98,48\% das "milhões de contribuições" são constituídas por mais de 11,9 milhões de cliques de resposta aos questionários de múltipla escolha sobre a clareza do texto e a pertinência/relevância dos objetos de aprendizagem. As contribuições efetivas, comentários e sugestões de inclusão e modificação do texto, representam apenas $1,52 \%$ do total de "contribuições".
\end{abstract}

É importante sublinhar o fato de que, nesta consulta pública, se opinava de acordo com os tópicos do texto/documento. Isto é, não era esperado que as contribuições localizadas questionassem ou criticassem ou propusessem sobre a estrutura geral ou sua concepção. Neste momento, a ANPEd se manifesta afirmando que a primeira versão apresentada:

Não contempla as dimensões de diversidade na educação brasileira, o que coloca em risco de retrocesso toda política educacional e ambiental no país, expressa hoje na Resolução 2/2012 do CNE que estabelece as Diretrizes Curriculares para a Educação Ambiental. Os associados afirmam seu posicionamento contrário à Base Nacional Comum Curricular tanto pela sua metodologia de elaboração quanto às evidentes implicações nos processos de avaliação de ensino aprendizagem, na homogeneização das matrizes curriculares, na formação de professores e na autonomia. (ANPEd, 2015, p. 1)

Ainda de acordo com Aguiar (2018, p. 11) "as contribuições foram sistematizadas por profissionais da Universidade de Brasília (UnB) e da Pontifícia Universidade Católica do Rio de Janeiro (PUC-RJ), e subsidiaram o MEC na elaboração da segunda versão". Falta, no entanto, transparência em relação aos procedimentos de leitura, sistematização e compartilhamento mobilizados para a produção da segunda versão (AGUIAR, 2018; CÁSSIO, 2019). Essa versão foi posta em discussão por cerca de nove (9) mil educadores no âmbito de seminários realizados pela União Nacional dos Dirigentes Municipais de Educação (Undime) e pelo Conselho Nacional de Secretários de Educação (Consed), no período de Junho a Agosto de 2016:

Os 27 seminários estaduais da segunda versão adotaram uma metodologia mais complexa para a coleta das contribuições dos 9.275 representantes das redes de ensino. Utilizando questionários abertos e de múltipla escolha, em diversos turnos, foram coletados comentários e sugestões por componente curricular e por Etapa da Educação Básica. As planilhas de sistematização por estado e o relatório-síntese das 
contribuições produzidos por Undime e Consed, mostram um grande número de críticas aos textos introdutórios, mas engajamentos desiguais nas contribuições referentes aos componentes curriculares. A partir dessas contribuições é que teria sido produzida a terceira versão da Base. (CÁSSIO, 2019, p. 28)

Neste ponto, destacam-se duas críticas ao processo de elaboração da Base: primeira, sobre o documento não incluir o Ensino Médio, descaracterizando o que era esperado, inclusive por representantes do Conselho Nacional de Educação (CNE), à época (AGUIAR, 2018); segunda, pela sistematização feita a partir dos seminários que, em alguma medida, os desconsiderava. Evidência disso é o fato de que a maior parte das modificações feitas na segunda versão a partir dos seminários "consiste de supressões no texto baseadas não no relatório-síntese de contribuições ou nas planilhas de sistematização dos seminários estaduais, mas no documento que explicita o posicionamento conjunto de Undime e Consed" (CÁSSIO, 2019, p. 29). Um exemplo dessa afirmação é o modo como a Pedagogia das Competências é sugerida para a terceira versão: "embora não tenha sido mencionado nos Seminários, o Consed avalia que o currículo do Ensino Médio deva ser organizado por competências" (2019, p. 30).

Por esses motivos o mesmo autor afirma que "é provável que os seminários estaduais tenham sido o esforço mais significativo, mas também o mais vão, de construção participativa do texto da BNCC" (CÁSSIO, 2019, p. 30). A despeito de toda crítica feita pelas associações científicas (VALLE, 2020), consolida-se a terceira versão da BNCC, tramitando de forma aligeirada até sua aprovação, ao fim de 2017:

A proposta da terceira versão, diferente das anteriores, já excluía o Ensino Médio e
trazia uma ruptura com a ideia de educação básica. O CNE promoveu uma audiência
em cada uma das cinco regiões do Brasil de junho a setembro de 2017, da qual
participaram entidades, professores e interessados. De setembro a dezembro de 2017,
a base nacional comum curricular tramitou no CNE de forma não transparente e foi
aprovada desconsiderando a construção já produzida pelas instituições educacionais
comprometidas com a educação pública de qualidade social e sob forte resistência de
três conselheiras, representantes de entidades nacionais, que votaram contra a BNCC,
assim como diversas instituições e associações de docentes e pesquisadores
manifestaram sua oposição a BNCC. A aprovação de uma política pública de forma
antidemocrática, sem transparência e sem ampla discussão com a sociedade
brasileira revela o modus operandi desses sujeitos individuais e coletivos. (ARELARO,
PERONI \& CAETANO, 2019, p. 43)

Em síntese, convergimos para a perspectiva de que, "enquanto processo histórico", conforme destacam Dourado \& Siqueira (2019, p. 294), "a BNCC não foi consensuada, não foi pactuada e, portanto, apresenta vários questionamentos acerca de sua legitimidade". Um desses questionamentos se dá sobre a prerrogativa de "tornar um conjunto de conhecimentos, habilidades e competências, que não é, ainda, nem comum, nem nacional, comum e nacional através da 


\section{revemop}

obrigatoriedade de seu ensino" (CURY, REIS \& ZANARDI, 2018, p. 60). Tal perspectiva, crítica à legitimidade dessa política curricular, nos conduz à tentativa de compreender como esse modus operandi, a que se referem Arelaro, Peroni \& Caetano (2019), se relaciona com a construção do texto de Matemática.

\section{Contexto e dilemas da Base Nacional Comum Curricular de Matemática}

Diferentes autores contribuíram para a abordagem que dedicaremos ao modo como a Matemática é apresentada na BNCC (PINTO, 2017; SANTOS, 2018; FREITAS et al., 2019; BIGODE, 2019; MALHEIROS \& FORNER, 2020). Concordamos com a afirmação de Bigode (2019, p. 123) de que se trata de uma discussão que "pode ser feita de múltiplas perspectivas, da visão epistemológica sobre a natureza do pensamento matemático à concepção didática que veicula". O mesmo autor aponta para a orientação ideológica do documento, "expressa numa visão que reduz a matemática a uma coleção estanque de itens que não passam de descritores de avaliação, agora rebatizados de "habilidades" (BIGODE, 2019, p. 123).

Sob nossa perspectiva, o trabalho de Pinto (2017, p. 1058), considerando a primeira e a segunda versões da Base, sinaliza duas fragilidades: a primeira, em relação ao modo como a autoria docente foi secundarizada no decorrer do processo, "deixando dúvidas quanto ao acolhimento das sugestões apresentadas por professores e pesquisadores"; a segunda, em relação "ao silêncio do documento BNCC em relação aos aspectos teórico-metodológicos já consolidados no campo da Educação Matemática, [...] da Etnomatemática, da História da Matemática e da Modelagem Matemática" (p. 1059). Ambas as fragilidades observadas convergem para o que outros trabalhos afirmam em relação à terceira e última versão do documento (BIGODE, 2019; VALLE, 2019), fundamentando afirmações como a de Santos (2018, p. 141) de que "os subalternos não têm voz política ou se têm voz esta não é ouvida". Nesse sentido, cabe resgatar o seguinte posicionamento de Muniz ${ }^{7}$, como leitor crítico:

[...] Faltam as perspectivas históricas e da etnomatemática, que não são contempladas na BNC. Assim, valores sociais, culturais e afetivos do aprender matemática não estão explicitados na aprendizagem escolar da matemática proposta pela BNC, não trazendo de forma explícita as tendências da Educação Matemática, tais como o enfoque histórico, cultural, comunicacional, lúdico, assim como as novas tecnologias que, quando presentes são marginais e alegóricas. Em síntese, parece haver um

7 Professor da Universidade de Brasília (UnB) e ex-presidente da Sociedade Brasileira de Educação Matemática (SBEM). 
silenciamento na proposta do que é extraescolar, dos aspectos da história da matemática, dos temas transversais. (MUNIZ apud BIGODE, 2019, p. 132)

No trabalho de Freitas et al. (2019, p. 287), dedicado ao estudo das competências da BNCC, identifica-se outra contribuição que interessa ao escopo deste trabalho: "as orientações metodológicas querem transparecer um ar de neutralidade, sem que o documento assuma uma concepção teórica explícita". Aprofundaremos essa perspectiva ao abordar a ausência da pluralidade de concepções pedagógicas, mais adiante. Cabe-nos, por enquanto, ressaltar a crítica, relacionada à afirmação apresentada, de que "a construção da base partiu do zero" (BIGODE, 2019, p. 129), ignorando as políticas curriculares e de formação de professores anteriores:

No que diz respeito às aprendizagens matemáticas, com base na perspectiva teórico-epistemológica, quanto metodológica da Educação Matemática, revela, em muitos aspectos, um certo retrocesso em relação aos avanços conquistados nos últimos documentos e políticas do MEC, em especial dos PCN, GESTAR, Direitos de Aprendizagem e Desenvolvimento, e mais, recentemente, do PNAIC de matemática. Além disso, conhecimentos fundamentais consolidados por meio da pesquisa científica no campo da Educação Matemática não são contemplados na proposta. Ao contrário, vemos alguns retrocessos inexplicáveis e insustentáveis. (MUNIZ apud BIGODE, 2019, p. 129, grifos nossos)

Parte dos retrocessos mencionados no excerto anterior são denunciados por Malheiros \& Forner (2020), cuja reflexão crítica sobre a BNCC é construída a partir do referencial teórico de Paulo Freire. 0 estudo dos autores evidencia que "o modo como o documento foi aprovado, de forma impositiva e antidialógica, com intuito de nortear o trabalho docente, e a forma como ele tem chegado nas escolas evidencia, para nós, um movimento de retrocesso para a Educação Básica" (MALHEIROS \& FORNER, 2020, p. 11). Tais autores também endereçam críticas ao modo linear e fragmentado como o conteúdo de matemática é apresentado no documento. Um exemplo pode ser observado no seguinte excerto: enquanto "para $01^{\circ}$ ano, a BNCC prevê que os estudantes aprendam até o número 100 e desenvolvam operações como adição considerando apenas esse conjunto numérico", "para o $2^{\circ}$ ano, a BNCC estipula que os estudantes aprendam até o número 10.000 e, novamente, os demais conteúdos devem ser pautados nesse limite de números" (MALHEIROS \& FORNER, 2020, p. 11). Convergimos, então, para os questionamentos apresentados por ambos no trabalho citado a partir do exemplo: "por que definir esses limites de números a serem aprendidos? Com base em que estudos?" (p. 12).

No mesmo sentido, Bigode (2019, p. 134) traz outros questionamentos pertinentes: "Introduz-se o conceito de múltiplo no $6^{\circ}$ ano, mas a resolução de problemas sobre múltiplos aparece somente no $7^{\circ}$ ano. Como se pode aprender um conceito apartado dos problemas que 0 


\title{
revemop
}

geram?". Além de outros exemplos de incongruências, Bigode (2019, p. 127) também traz como contribuição a denúncia de que as perspectivas críticas dos especialistas da área de Matemática não foram consideradas e/ou incorporadas à construção do documento curricular. No parecer de Passos $^{8}$, lemos que:

\begin{abstract}
O PNAIC constituiu um avanço no campo da matemática, pois, pela primeira vez no País,houve a mobilização de todos os sistemas públicos de ensino para a formação docente dos professores que atuam no ciclo de alfabetização. Foi um alto investimento, tanto na elaboração dos cadernos - denominado Pacto de Matemática - quanto na formação docente. No entanto, esse documento e os seus desdobramentos não foram considerados na BNCC, pois não se considerou o ciclo de alfabetização, além de ignorar a perspectiva interdisciplinar do material do PNAIC. [...] 0 documento não traz discussão alguma sobre a natureza do conhecimento matemático, nem tampouco do conhecimento matemático escolar e do papel do professor no processo de aprendizagem do aluno. Nos anos iniciais, ficamos com a percepção de um espontaneísmo com usos de estratégias pessoais, sem sistematização/formalização de conceitos. Defendemos que, no processo de elaboração conceitual, é fundamental que o estudante se expresse pela língua materna, utilize estratégias e registros pessoais, mas, gradativamente, seja posto em contato com registros simbólicos com compreensão e significação.
\end{abstract}

A autora reafirma, em seu parecer, alguns dos pontos sinalizados anteriormente, tais como sua crítica à descontinuidade dos princípios e procedimentos mobilizados nas políticas educacionais anteriores e à ausência de uma orientação explícita que garanta a coesão da proposta e sua compreensão. Reconhecer tais aspectos no documento, síntese de uma concepção de política curricular, nos permite, adiante, identificar suas ausências e discuti-las propositivamente.

\section{Ausências da Base Nacional Comum Curricular de Matemática}

A indolência da razão, que desperdiça a experiência, ocorre, de acordo com Santos (2006, p. 95-96), de quatro formas:

[...] a razão impotente, aquela que não se exerce porque pensa que nada pode fazer contra uma necessidade concebida como exterior a ela própria; a razão arrogante, que não sente necessidade de exercer-se porque se imagina incondicionalmente livre e, por conseguinte, livre da necessidade de demonstrar sua própria liberdade; a razão metonímica, que se reivindica como a única forma de racionalidade e, por conseguinte, não se aplica a descobrir outros tipos de racionalidade ou, se o faz, fá-lo apenas para as tornar em matéria-prima; e a razão proléptica, que não se aplica a pensar o futuro, porque julga que sabe tudo a respeito dele e o concebe como uma superação linear, automática e infinita do presente.

8 Professora da Universidade Federal de São Carlos (UFSCar), coautora de um dos cadernos do Pacto Nacional pela Alfabetização na Idade Certa (PNAIC) de Matemática. Parecer disponível em: http://basenacionalcomum.mec.gov.br/images/relatorios-analiticos/Carmen_Lucia_Brancaglion_Passos.pdf 
Para o sociólogo, a razão metonímica produz ou legítima as cinco principais formas de não-existência identificadas em seu trabalho: "o ignorante, o residual, 0 inferior, o local e 0 improdutivo" (SANTOS, 2006, p. 104). Sua afirmação de que essas ausências/inexistências são produzidas ativamente se justifica porque "as realidades que elas conformam estão apenas presentes como obstáculos em relação às realidades que contam como importantes, sejam elas realidades científicas, avançadas, superiores, globais ou produtivas" (p. 104). Percebê-las como "partes desqualificadas de realidades homogêneas" contribui para a compreensão de que "a produção social destas ausências resulta na subtração do mundo e na contração do presente e, portanto, no desperdício da experiência" (SANTOS, 2006, p. 105).

Conforme afirmamos anteriormente, nosso texto, nesta pesquisa, se orienta pela Sociologia das Ausências na medida em que esta "visa identificar o âmbito dessa subtração e dessa contração de modo que as experiências produzidas como ausentes sejam libertadas dessas relações de produção e, por essa via, se tornem presentes" (SANTOS, 2006, p. 106). Em nosso caso, o estudo sobre as ausências na/da BNCC, a partir da perspectiva enunciada, corresponde à identificação das subtrações/contrações que constituíram o documento e a política curricular nele expressa. Sob a perspectiva teórico-metodológica que adotamos, esse movimento implicou identificar os principais elementos críticos subjacentes tanto às notas e ofícios elaborados pelas associações científicas da Educação e antes mencionados, como à literatura dedicada ao processo de elaboração curricular da BNCC de Matemática. Este estudo nos permitiu a identificação de três ausências: a ausência da autoria docente, a ausência da pluralidade de concepções pedagógicas e a ausência das perspectivas socioculturais da Educação Matemática. A seguir, tratamos de cada uma delas.

\subsection{A ausência da autoria docente}

A primeira ausência identificada depreende-se do processo de elaboração da própria política curricular instituída por meio da BNCC. Conforme diferentes trabalhos sinalizaram, incluindo as notas e ofícios encaminhados ao Ministério da Educação pela ANPEd e pela ABdC, embora tenham sido abertos momentos da construção do documento à participação docente, essa participação se configurou, desde o início, como limitada e restrita às opções preestabelecidas (CÁSSIO, 2019; DOURADO \& AGUIAR, 2018). Como vimos anteriormente, a investigação de Cássio $(2019$, p. 27) sobre os microdados da consulta pública mostrou que os comentários que sinalizam sugestões de inclusão ou modificação do texto representavam somente $1,52 \%$ do total de "contribuições". 
Em Cássio (2019), mas também em Dourado \& Aguiar (2018) e em Cury, Reis \& Zanardi (2018), outra crítica à ausência efetiva de participação docente no processo de elaboração curricular da BNCC, de um modo geral, consiste no fato de que desde a consulta pública, online, até os pareceres de especialistas e seminários estaduais organizados como espaços de garantia de ampla participação, não houve alteração substantiva ou efetiva do texto-documento decorrente da participação docente. Este tem sido o principal aspecto salientado pelas críticas à BNCC que explicita desde sua apresentação que "foi preparada por especialistas de cada área do conhecimento, com a valiosa participação crítica e propositiva de profissionais de ensino e da sociedade civil" (BRASIL, 2017, p. 7). A falta de transparência da relação entre as etapas anunciadas para elaboração do documento e as versões que foram apresentadas também é apontada como uma fragilidade de sua construção, em especial no que se refere à participação docente, pública e efetiva (CURY, REIS \& ZANARDI, 2018).

Para adensar a crítica à construção ativa que produziu a autoria docente como ausente no contexto da política evidenciada, remetemo-nos ao excerto em que Cássio (2019, p. 30) trata das audiências públicas realizadas sobre o documento para o Ensino Médio:

\begin{abstract}
A audiência da região Sudeste, realizada em São Paulo/SP (08 jun. 2018), teve 0 plenário ocupado por professores e secundaristas antes mesmo de ser iniciada. A nota oficial do CNE informou que a audiência fora "cancelada, pois grupos de manifestantes impediram que o tema pudesse ser discutido com a devida profundidade". O CNE não percebeu, mas esta foi a primeira audiência pública da Base em que participaram aqueles que, até então, não haviam sido escutados.
\end{abstract}

No decorrer de todo o processo foram privilegiados outros atores ${ }^{9}$ e procedimentos que simularam a participação docente, sem considerá-la efetivamente na escrita do texto ou na construção da política curricular. Trata-se do que Saul (1998) classifica como a "Pedagogia dos Diários Oficiais" (SAUL, 1998), negadora da ação e da criação cotidianas por parte de quem habita o "chão da escola". Compreendemos o currículo e suas políticas, ao invés disso,

[...] não como um produto, pronto, acabado, para ser consumido, mas como um processo em constante construção, que se faz e se refaz. Fundamentalmente, como um caminho onde a participação dos atores que interagem no processo educativo é condição da sua construção. (SAUL, 1998, p. 155, grifos nossos)

Ao invés de compreender a participação dos atores que interagem no processo educativo como condição para construção curricular, conforme lemos no excerto, o processo de elaboração

9 Arelaro, Peroni \& Caetano (2019) elucidam quais atores foram privilegiados durante o processo de elaboração do documento. 
da BNCC secundarizou essa participação. De acordo com Macedo (2018, p. 31), ao secundarizála "estamos jogando fora uma experiência de formação de professores e de pesquisa das Universidades brasileiras para 'comprar' parcerias internacionais contestadas em seus cenários nacionais e que pouco conhecem da nossa tradição". Assim, a BNCC se inscreve no conjunto designado por Alves et al (2002, p. 41) como parte substantiva das propostas curriculares brasileiras, que "tem sido incapaz de incorporar essas experiências, pretendendo pairar acima da atividade prática dos sujeitos que constituem a escola". Ao deixar de incorporá-las, a política curricular desperdiça tais experiências, produzindo-as ativamente como ausentes/inexistentes. Essa é a expressão da razão indolente que, neste contexto, reforça a dicotomia entre planejadores e executores do currículo, destituindo a docência de sua dimensão de criação, planejamento e organização da ação pedagógica.

No atual cenário brasileiro, reforçar essa dicotomia implica, inclusive, a desprofissionalização da docência, estigmatizada pelos "maus resultados" ou pela "conjuntura de crise da educação" que, vez ou outra, constituíram argumentos em favor da instituição da própria Base (CURY, REIS \& ZANARDI, 2018).

\subsection{A ausência da pluralidade de concepções pedagógicas}

Nas duas páginas dedicadas aos Fundamentos Pedagógicos da BNCC, lemos que "o foco no desenvolvimento de competências tem orientado a maioria dos Estados e Municípios brasileiros e diferentes países na construção de seus currículos" (BRASIL, 2017, p. 13). Na nota de rodapé, contudo, lemos que "segundo a pesquisa elaborada pelo Cenpec, das 16 Unidades da Federação cujos documentos curriculares foram analisados, 10 delas explicitam uma visão de ensino por competências, recorrendo aos termos 'competência' e 'habilidade' (ou equivalentes, como 'capacidade', 'expectativa de aprendizagem' ou 'o que os alunos devem aprender')" (BRASIL, 2017, p. 13, rodapé). Não se pode inferir que a pedagogia das competências tenha orientado "a maioria dos Estados e Municípios brasileiros" na construção de seus currículos, simples e matematicamente porque dez (10) estados não representam a maioria dos estados brasileiros.

Vimos anteriormente que a inserção da Pedagogia das Competências durante o processo de elaboração da BNCC decorreu da sugestão feita pela Undime e pelo Consed no momento de sistematização dos seminários estaduais (CÁSSIO, 2019; VALLE, 2020). Essa sugestão, contudo, não teve amparo na participação nos seminários, o que evidencia, inclusive, a ausência da autoria docente, mencionada antes, assim como a simulação de participação construída ao longo do 


\title{
revemop
}

processo. Nesse sentido, cabe-nos enfatizar, conforme Arelaro, Peroni \& Caetano (2019, p. 46), que "essa é a primeira vez que o MEC apresenta uma proposta oficial, afirmando que ela será obrigatória, contrariando dispositivo constitucional que garante o 'pluralismo de ideias e de concepções pedagógicas', como direito do ensino brasileiro (art. 206, III, Constituição Federal, BRASIL,1988)".

Identificamos, portanto, outra ausência produzida ativamente no contexto dessa política: a ausência da pluralidade de concepções pedagógicas. Assim como os excertos anteriores, as associações científicas também manifestaram suas críticas à essa ausência:

\begin{abstract}
Não respeita o princípio do pluralismo de ideias e concepções pedagógicas, assumindo uma, e somente uma em sua formulação. Sendo conteudista e disciplinarista, fere o princípio da valorização da experiência extraescolar e a formação para o exercício da cidadania. Investe no controle externo da gestão e do fazer docente, por meio de avaliações externas (de alunos, professores e gestores) aliadas à responsabilização local pelos resultados, comprometendo o princípio da gestão democrática, a formulação participativa do Projeto Pedagógico e o princípio da valorização docente. (ABdC, 2017, p. 2)
\end{abstract}

Compreender a forma como essa ausência é produzida ativamente passa pela compreensão de que o "pluralismo de ideias e concepções pedagógicas", assegurado constitucionalmente, fica comprometido diante do texto de uma política curricular nacional, "obrigatória", que assume uma única concepção pedagógica. Todas as demais concepções são produzidas ativamente como inexistentes, como alternativas menos críveis, por meio do frágil argumento de que a maioria dos estados e municípios já tem utilizado a Pedagogia das Competências. Nesse sentido, convergimos para o posicionamento da $\operatorname{ABdC}(2018$, p. 1) de que: "A BNCC não tem o poder de exaurir as disputas no e do campo curricular, lócus privilegiado de disputas no qual diferentes saberes e vivências se colocam frente às prescrições".

Ademais, cumpre-nos salientar que, segundo Dourado \& Siqueira (2019, p. 297), "a pedagogia das competências reafirma o modelo de gestão empresarial de responsabilização individual dos sujeitos frente aos processos de aprendizagem e apropriação do conhecimento". Esse modelo de centralização curricular a partir de uma concepção de aprendizagem cognitivista indica, para os autores, que "o conhecimento prático requerido nas habilidades e competências da BNCC é aquele marcado pela lógica pragmática, utilitarista e reducionista" (p. 298). Desse modo, resta-nos considerar como insuficiente e questionável a escolha de uma única concepção pedagógica para orientar os sistemas de ensino brasileiros. Sobre essa escolha única, que invisibiliza a pluralidade de concepções pedagógicas de que trata o texto constitucional, se avolumam outras críticas feitas à Pedagogia das Competências: 
Em textos oficiais recentes, a palavra "competência" corre sério risco de ser coisificada como novo habitante do bestiário pedagógico que, querem nos fazer crer, são coisas que a educação deve desenvolver. Esse risco pode ter graves consequências pedagógicas, principalmente porque, em alguns textos, competências são contrapostas a conhecimentos, como se as escolas de formação geral [...] devessem se preocupar mais com a constituição daquelas do que com o ensino destes, como se fosse possível alguém tornar-se um matemático competente pelo desenvolvimento de uma "coisa" que se chama "competência matemática" distinta do estudo intensivo de tópicos da matemática. (AZANHA, 2006, p. 167).

Gottschalk (2002) e Pereira (2015) apresentam trabalhos que avançam na crítica elaborada no excerto anterior, a partir de uma perspectiva wittgensteiniana, que critica a cisão construída no contexto da Pedagogia das Competências entre saber algo e saber fazê-lo, como se houvesse etapas distintas da construção de conhecimento, segundo as quais primeiro aprenderíamos seus enunciados e, posteriormente, aprenderíamos a mobilizá-los.

As proposições sobre competências não são recebidas - não são usadas - no campo pedagógico como confiáveis porque fundamentadas (ou quase) nas ciências cognitivas. Elas atuam antes como normas, fundamentos em relação aos quais as questões do universo escolar devem prestar contas e eventualmente ganhar sentido. A adesão demandada por essa pedagogia visa, desse modo, a redesenhar nossa imagem de mundo escolar. (PEREIRA, 2015, p. 240)

Encontramos a expressão dessa concepção no texto da BNCC dedicado a estabelecer "aquilo que os estudantes devem aprender na Educação Básica, o que inclui tanto os saberes quanto a capacidade de mobilizá-los e aplicá-los." (BRASIL, 2017, p.12). A seguir, apresentamos dois trechos da BNCC de Matemática, relativos ao $7^{\circ}$ ano do Ensino Fundamental, como ilustrações das afirmações anteriores:

\begin{tabular}{|c|l|l|}
\hline $\begin{array}{c}\text { Unidades } \\
\text { temáticas }\end{array}$ & \multicolumn{1}{|c|}{ Objetos de conhecimento } & \multicolumn{1}{|c|}{ Habilidades } \\
\hline \multirow{4}{*}{ Números } & $\begin{array}{l}\text { Múltiplos e divisores de um } \\
\text { número natural }\end{array}$ & $\begin{array}{l}\text { (EF07MA01) Resolver e elaborar problemas com números } \\
\text { naturais, envolvendo as noções de divisor e de múltiplo, } \\
\text { podendo incluir máximo divisor comum ou mínimo múltiplo } \\
\text { comum, por meio de estratégias diversas, sem a aplicação } \\
\text { de algoritmos. }\end{array}$ \\
\cline { 2 - 4 } & $\begin{array}{l}\text { Cálculo de porcentagens e de } \\
\text { acréscimos e decréscimos } \\
\text { simples }\end{array}$ & $\begin{array}{l}\text { (EF07MA02) Resolver e elaborar problemas que envolvam } \\
\text { porcentagens, como os que lidam com acréscimos e } \\
\text { decréscimos simples, utilizando estratégias pessoais, cálculo } \\
\text { mental e calculadora, no contexto de educação financeira, } \\
\text { entre outros. }\end{array}$ \\
\cline { 2 - 3 } & $\begin{array}{l}\text { Números inteiros: usos, } \\
\text { história, ordenação, } \\
\text { associação com pontos da reta } \\
\text { numérica e operações }\end{array}$ & $\begin{array}{l}\text { (EF07MA03) Comparar e ordenar números inteiros em } \\
\text { diferentes contextos, incluindo o histórico, associá-los a } \\
\text { pontos da reta numérica e utilizá-los em situações que } \\
\text { envolvam adição e subtração. }\end{array}$ \\
\hline
\end{tabular}




\begin{tabular}{|c|c|c|}
\hline & & $\begin{array}{l}\text { (EF07MA04) Resolver e elaborar problemas que envolvam } \\
\text { operações com números inteiros. }\end{array}$ \\
\hline \multirow[t]{2}{*}{ Geometria } & $\begin{array}{l}\text { Transformações geométricas } \\
\text { de polígonos no plano } \\
\text { cartesiano: multiplicação das } \\
\text { coordenadas por um número } \\
\text { inteiro e obtenção de } \\
\text { simétricos em relação aos } \\
\text { eixos e à origem }\end{array}$ & $\begin{array}{l}\text { (EF07MA19) Realizar transformações de polígonos } \\
\text { representados no plano cartesiano, decorrentes da } \\
\text { multiplicação das coordenadas de seus vértices por um } \\
\text { número inteiro. } \\
\text { (EF07MA20) Reconhecer e representar, no plano cartesiano, } \\
\text { o simétrico de figuras em relação aos eixos e à origem. }\end{array}$ \\
\hline & $\begin{array}{l}\text { Simetrias de translação, } \\
\text { rotação e reflexão }\end{array}$ & $\begin{array}{l}\text { (EF07MA21) Reconhecer e construir figuras obtidas por } \\
\text { simetrias de translação, rotação e reflexão, usando } \\
\text { instrumentos de desenho ou softwares de geometria } \\
\text { dinâmica e vincular esse estudo a representações planas de } \\
\text { obras de arte, elementos arquitetônicos, entre outros. }\end{array}$ \\
\hline
\end{tabular}

Tabela 01: Habilidades e objetos de conhecimento relativos às unidades temáticas de Números e Geometria para 0 $7^{\circ}$ ano do Ensino Fundamental. Fonte: BRASIL, 2017, p. 307-308.

O questionamento enunciado por Azanha (2006, p. 167) pode ser desdobrado na leitura dos trechos apresentados: o que é, por exemplo, a habilidade EF07MA19 que não seja, para a finalidade do trabalho pedagógico, a abordagem de seu objeto de conhecimento correspondente? Ou ainda: é possível "saber" simetrias de translação, rotação e reflexão sem "saber" reconhecêlas e construí-las? Reconhecê-las e construí-las, neste caso, corresponde à "aplicação" deste saber? O que é, então, esse saber que não inclui sua própria mobilização nos contextos pertinentes? Na BNCC de Matemática, está explícita essa cisão entre o "saber" como objetos de conhecimento e o "saber aplicado/mobilizado" como habilidades. Cisão fundamentada no pressuposto equivocado de que exista algo como o "saber em si" e o "saber em uso".

Os trabalhos de Gottschallk (2002) e Pereira (2015) contribuem para o adensamento dessa crítica, sob uma perspectiva wittgensteiniana,

O significado dos conceitos está no próprio uso que se faz deles, e não que haja um significado essencial que surge do problema, como se o conhecimento matemático surgisse da situação empírica e, portanto, "significativa". Desconsiderar isso é exigir do aluno um desempenho para o qual ele está logicamente impossibilitado, com conseqüências desastrosas para o aprendizado - como sentimentos de incompetência ou "falta de talento" para a matemática... (GOTTSCHALK, 2002, p. 143)

Se o significado dos conceitos matemáticos está no uso que se faz deles, então aprender tais conceitos envolve necessariamente compreendê-los e mobilizá-los nos contextos em que são utilizados. Não são etapas distintas da aprendizagem como a versão adotada da Pedagogia das Competências faz parecer. 
A pluralidade de concepções pedagógicas foi produzida ativamente como ausente no decorrer de toda a elaboração da BNCC, conduzindo-nos à homogeneização dessa versão da Pedagogia das Competências, a partir da argumentação de que este ideário já orientava "a maioria dos estados".

\title{
5.3 A ausência das perspectivas socioculturais da Educação Matemática
}

A terceira ausência identificada durante a pesquisa consiste na ausência das perspectivas socioculturais ${ }^{10}$ da Educação Matemática. Esta ausência, em particular, já foi sinalizada em trabalhos anteriores (PINTO, 2017; SANTOS, 2018; BIGODE, 2019; VALLE, 2019; MALHEIROS \& FORNER, 2020) e também nos pareceres técnicos de diferentes especialistas responsáveis pela leitura crítica das versões preliminares:

\begin{abstract}
Julgamos relevante destacar novamente a ausência total de referências explícitas a tendências em Educação Matemática, como a Modelagem, a Etnomatemática, Resolução de Problemas, uso de Tecnologias Digitais e tantas outras. Parece estranho que um documento que valoriza a interdisciplinaridade não se refira de maneira clara e objetiva às tendências de Educação Matemática debatidas, pesquisadas tanto no Brasil como no exterior, como: Etnomatemática, Informática na Educação Matemática, Modelagem Matemática, Educação Matemática Crítica, Abordagem histórico-cultural para o ensino de matemática. A aparente ênfase no trabalho interdisciplinar explicitada na apresentação do documento não se confirma quando se apresentam os objetivos de aprendizagem, isto é, esses se mostram como "uma matemática voltada a si mesma" (PASSOS, 2016, p. 23)
\end{abstract}

Esta ausência causa um estranhamento adicional devido ao fato de que os movimentos ligados à defesa da BNCC e de sua institucionalização argumentaram em diferentes momentos que a política curricular ensejada no documento não romperia a continuidade das políticas educacionais consolidadas nas últimas décadas, remetendo-nos, inclusive aos Parâmetros Curriculares Nacionais (PCN) e as Diretrizes Curriculares Nacionais (DCN). Ambos os documentos, contudo, acolhem as perspectivas socioculturais da Educação Matemática, dentre as quais nomeadamente a Etnomatemática (VALLE, 2019). As Diretrizes Curriculares Nacionais para a Educação das Relações Étnico-Raciais e para o Ensino de História e Cultura Afro-Brasileira e Africana (BRASIL, 2004) caracterizam a Etnomatemática em seu papel de descrever contribuições que permitam às escolas superar o etnocentrismo dos currículos.

10 Consideramos, para caracterizá-las, as abordagens e concepções relacionadas às perspectivas "socioetnoculturais", conforme a identifica Fiorentini (1995). 
As perspectivas socioculturais da Educação Matemática, de um modo geral, e a Etnomatemática, em particular, respondem à demanda apresentada no documento de que "cabe às escolas incluir no contexto dos estudos e atividades, que proporciona diariamente, também as contribuições histórico-culturais dos povos indígenas e dos descendentes de asiáticos, além das de raiz africana e européia" (BRASIL, 2004, p. 17). Nesse contexto, sugere-se a Etnomatemática por sua compreensão de que os conhecimentos que hoje relacionamos com a matemática "incluem, invariavelmente, em todos os tempos e lugares no mundo, estratégias de observação, de comparação, de classificação, de avaliação, de quantificação, de mensuração, representação, inferência e comunicação" (D'AMBROSIO, 2020, p. 7, tradução nossa). Tais sistemas de conhecimentos complexos têm sido sistematicamente invisibilizados e eliminados do debate público curricular até muito recentemente na história brasileira (VALLE, 2019), quando passaram a ser explicitados nos documentos curriculares mencionados. A BNCC de Matemática, contudo, produz ativamente tais perspectivas como ausentes ao desconsiderá-las. Mesmo sem quaisquer referências às perspectivas socioculturais da Educação Matemática, a BNCC apresenta como competências específicas de Matemática as seguintes:

\footnotetext{
Reconhecer que a Matemática é uma ciência humana, fruto das necessidades e preocupações de diferentes culturas, em diferentes momentos históricos, e é uma ciência viva, que contribui para solucionar problemas científicos e tecnológicos e para alicerçar descobertas e construções, inclusive com impactos no mundo do trabalho. $[\ldots]$

Desenvolver e/ou discutir projetos que abordem, sobretudo, questões de urgência social, com base em princípios éticos, democráticos, sustentáveis e solidários, valorizando a diversidade de opiniões de indivíduos e de grupos sociais, sem preconceitos de qualquer natureza. (BRASIL, 2017, p. 267)
}

Não se atinge a competência de reconhecer que a matemática é construção humana sem as perspectivas socioculturais da Educação Matemática, porque foram tais perspectivas que pautaram esse debate nas últimas décadas. $O$ mesmo vale para projetos que abordem questões de urgência social ou de reconhecer a matemática como conhecimento humano, sociocultural, pois não há, no documento, quaisquer referências às maneiras como se espera realizar esse trabalho ou às linhas de pesquisa que têm endereçado tais questões no contexto da Educação Matemática (VALLE, 2019). A ausência das perspectivas socioculturais se produz num contexto de negligência em relação à própria diversidade teórica e epistemológica dos debates e das pesquisas sobre educação, sobre currículo, conforme salientam, em nota, ANPEd \& ABdC (2015):

Registramos, seguidamente, que a diversidade teórica e epistemológica dos debates no campo da educação em geral e do currículo, particularmente nos últimos 40 anos, é desconsiderada no corpus teórico do documento, bem como a pluralidade 
epistemológica do mundo, e as diferentes formas de compreensão e de ação sobre ele que caracterizam nossa sociedade multicultural e multiétnica.

Esse entendimento converge para 0 que os textos de diferentes pareceristas que chamaram a atenção para "a falta de fundamentos sobre a natureza da matemática e o discurso vazio sobre a área, agravado pelo fato de que não foi explicado como a Matemática pode ser ao mesmo tempo área e componente curricular" (BIGODE, 2019, p. 133). A ausência das perspectivas socioculturais da Educação Matemática, produzida ativamente, contribui para essa fragilidade percebida na forma como a disciplina é apresentada, como uma série de tarefas compreendidas como habilidades matemáticas, descontextualizadas e sem enredo, cujo domínio assegura certa "competência".

\section{Considerações finais}

Na literatura sobre currículos e, particularmente, currículos de matemática no Brasil, identificase que "as decisões curriculares foram historicamente marcadas por ações governamentais e não oriundas de movimentos nascidos nas escolas, protagonizadas por professores ou pela sociedade civil" (PIRES \& SILVA, 2011, p. 58). Essa marca histórica de nossa "inexperiência democrática" (FREIRE, 1997) também se expressa na elaboração da Base Nacional Comum Curricular, de que trata este texto. 0 estudo nos permitiu, sob essa perspectiva, contribuir para a elucidação de três ausências produzidas ativamente nesse processo de elaboração: a ausência da autoria docente, a ausência da pluralidade das concepções pedagógicas e a ausência das perspectivas socioculturais da Educação Matemática.

Como vimos, "a sociologia das ausências visa criar uma carência e transformar a falta da experiência social em desperdício da experiência social" (SANTOS, 2006, p. 105).De tal modo, identificar tais ausências corresponde a um primeiro movimento de indagação desse desperdício. Existem políticas curriculares que acolhem e estimulam a autoria docente, a pluralidade das concepções pedagógicas e as perspectivas socioculturais mencionadas, porém são desperdiçadas durante a elaboração da BNCC. Nesse sentido, identificamos tais ausências primeiro, por compreendê-las como resultado da iniciativa dos grupos e dos procedimentos que organizaram o processo de elaboração; segundo para retirá-las da ausência que Ihes foi atribuída ou "ativamente produzida", para utilizarmos a expressão de Santos (2006). Para torná-las presentes, remetemo-nos à Sociologia das Ausências, acompanhada das Emergências de que trata o sociólogo português: "tornar-se presentes significa serem consideradas alternativas às experiências hegemônicas, a sua 


\section{revemop}

credibilidade poder ser discutida e argumentada e as suas relações com as experiências hegemônicas poderem ser objeto de disputa política" (SANTOS, 2006, p. 106).

Sob essa perspectiva, reconhecer que a autoria docente, a pluralidade de concepções pedagógicas e as perspectivas socioculturais da Educação Matemática são produzidas como ausências nos compromete, então, com a necessidade de torná-las presentes, fazê-las emergir, isto é, desinvisibilizá-las (OLIVEIRA, 2013). Esse movimento, orientado pela Sociologia das Ausências e das Emergências (SANTOS, 2002, p. 249), nos conduz, então à "demanda de subjetividades desestabilizadoras, subjetividades que se rebelem contra práticas sociais conformistas, rotinizadas e repetitivas, e se deixem estimular por experiências de limiar, ou seja por formas de sociabilidade excêntricas ou marginais". Essa demanda se traduz, neste nosso caso, por desinvisibilizar práticas de autoria docente, marcadamente plurais e híbridas em termos das concepções pedagógicas que lhes subjazem e, finalmente, práticas que mobilizem as perspectivas socioculturais da Educação Matemática. Mapeá-las, acompanhá-las, subsidiá-las, estimulá-las e compartilhá-las constituem movimentos que ampliam a institucionalidade de práticas que subvertem cada uma dessas ausências. Afinal, compreendemos:

\footnotetext{
Faz-se necessário não perder de vista que a exigência democrática de práticas sociais e curriculares horizontalizadas interditam a proposição de receitas a respeito de procedimentos e ações, sendo necessário considerar que a especificidade dos diferentes espaçostempos educativos exige que cada solução para o problema geral que é a de desenvolvimento de práticas curriculares de caráter emancipatório seja local para que seja legítima (OLIVEIRA, 2013, p. 19)
}

Por isso, revisitamos um dos movimentos de resistência promovidos pela ANPEd e pela ABdC no decorrer da elaboração da BNCC: a campanha "Aqui já tem currículo" dedicada a "valorizar as experiências curriculares que acontecem nos diferentes cotidianos das escolas e que resistem a muitas possibilidades de uma narrativa hegemônica curricular, como pretende o texto da BNCC" (ANPEd, 2015, p. 4). Durante a realização da campanha, diferentes escolas e redes públicas de ensino enviaram às entidades mencionadas e tornaram públicos os seus projetos curriculares, projetos político-pedagógicos e outras orientações curriculares construídas de forma artesanal e bastante singular em cada contexto escolar. 0 objetivo da campanha, a nosso ver, converge para o que parece ser uma consideração final deste trabalho, isto é, a necessidade de reconhecer práticas consistentes já em curso, que constituem a multiplicidade e a variedade dos currículos, considerando seus praticantes como interlocutores para a elaboração curricular traduz-se, portanto, num modo de enfrentamento das ausências atribuídas, em especial por políticas curriculares prescritivas e 
homogeneizantes que, por isso, não são suficientes diante da complexidade que caracteriza a Educação Básica brasileira.

\section{Referências}

AGUIAR, Márcia Ângela. Relato da resistência à instituição da BNCC pelo Conselho Nacional de Educação mediante pedido de vista e declarações de votos. In: DOURADO, Luiz Fernandes; AGUIAR, Márcia Ângela (orgs.). A BNCC na contramão do PNE 2014-2014: avaliação e perspectivas. Recife: ANPAE, 2018, p. 8-22.

ALVES, Nilda; MACEDO, Elizabeth; MANHÃES, Luiz Carlos; OLIVEIRA, Inês Barbosa de. Criar currículo no cotidiano. São Paulo: Cortez, 2002.

ANFOPE, Associação Nacional pela Formação dos Profissionais da Educação. Nota de Comissão Bicameral do Conselho Nacional de Educação sobre a Formação Inicial e Continuada de Professores. 2018. Disponível em: http://www.anfope.org.br/wpcontent/uploads/2018/05/ANFOPE-CNE-9abr-2018-.pdf Último acesso em: 05 Abril 2020.

ANPEd, Associação Nacional de Pós-graduação e Pesquisa em Educação. Ofício n. 138/2015 A Associação Nacional de Pós-Graduação e Pesquisa em Educação e a Base Nacional Comum Curricular. 2015. Disponível em: http://www.anped.org.br/sites/default/files/images/a_anped_e_a_bncc_versao_final.pdf acesso em: 05 Abril 2020.

ARELARO, Lisete Regina Gomes; PERONI, Vera Maria; CAETANO, Maria Raquel. BNCC: disputa pela qualidade ou submissão da educação? RBPAE, São Paulo, v. 35, n. 1, p. 35-56, 2019.

AZANHA, José Mário Pires. A formação do professor e outros escritos. São Paulo: Senac, 2006.

BIGODE, Antonio José Lopes. Base, que base? O caso da matemática. In: CÁSSIO, Fernando; CATELLI JR., Roberto. (orgs.). Educação é a Base? 23 educadores discutem a BNCC. São Paulo: Ação Educativa, 2019, p 123-144.

BRASIL. Diretrizes Curriculares Nacionais para a Educação das Relações Étnico-Raciais e para o Ensino de História e Cultura Afro-Brasileira e Africana - Brasília: Ministério da Educação, 2004.

BRASIL. Ministério da Educação. Base Nacional Comum Curricular (BNCC). 2017. Disponível em: <http://basenacionalcomum.mec.gov.br>. Último acesso em 03 Fev. 2021.

CÁSSIO, Fernando. Existe vida fora da BNCC? In: CATELLI Jr., Roberto; CÁSSIO, Fernando. (Orgs.). Educação é a Base? 23 educadores discutem a BNCC. São Paulo: Ação Educativa, 2019, p. 13-40.

CÁSSIO, Fernando; CATELLI JR., Roberto. (orgs.). Educação é a Base? 23 educadores discutem a BNCC. São Paulo: Ação Educativa, 2019.

CURY, Carlos Roberto Jamil; REIS, Magalo; ZANARDI, Teodoro Adriano. Base Nacional Comum Curricular: dilemas e perspectivas. São Paulo: Cortez, 2018. 
D'AMBROSIO, Ubiratan. Ethnomathematics: past and future. Revemop, Ouro Preto, v. 2, p. 1-14, 2020. DOI: https://doi.org/10.33532/revemop.e202002

DOURADO, Luiz Fernandes; AGUIAR, Márcia Ângela (orgs.). A BNCC na contramão do PNE 2014-2014: avaliação e perspectivas. Recife: ANPAE, 2018.

DOURADO, Luiz Fernandes; SIQUEIRA, Romilson Martins. A arte do disfarce: BNCC como gestão e regulação do currículo. RBPAE, v. 35, n. 2, p. 291-306, 2019.

FIORENTINI, Dario. Alguns modos de ver e conceber o ensino de matemática no Brasil. Revista Zetetiké, Campinas, v. 3, n. 4, p. 1-38, 1995.

FREIRE, Paulo. A educação na cidade. São Paulo: Cortez, 1997.

FREITAS, Fabrício Monte; BERTOLUCCI, Cristina Cavalli; ROVEDA, Crislaine; SILVA, João Alberto. Abrindo a caixa de Pandora: as competências da matemática na BNCC. RPEM, Campo Mourão, v.8, n.17, p. 265-291, 2019.

GOTTSCHALK, Cristiane. Uma reflexão filosófica sobre a matemática nos PCN. 154f. Tese (Doutorado em Filosofia da Educação) - Faculdade de Educação, Universidade de São Paulo, São Paulo, 2002.

LOPES, Alice Casimiro; MACEDO, Elizabeth. Teorias de currículo. São Paulo: Cortez, 2011.

LÜDKE, Menga; ANDRÉ, Marli. Pesquisa em Educação: abordagens qualitativas. São Paulo: EPU, 1986

MACEDO, Elizabeth. "A base é a base". E o currículo, o que é? In: DOURADO, Luiz Fernandes; AGUIAR, Márcia Ângela (Orgs.). A BNCC na contramão do PNE 2014-2024: avaliação e perspectivas. Recife: ANPAE, 2018, p. 28-33.

MALHEIROS, Ana Paula dos Santos; FORNER, Régis. Um olhar freireano para a Base Nacional Comum Curricular de Matemática. Olhar de professor, Ponta Grossa, v. 23, p. 1-14, 2020.

OLIVEIRA, Inês Barbosa. Políticas curriculares no contexto do golpe de 2016: debates atuais, embates e resistências. In: DOURADO, Luiz Fernandes; AGUIAR, Márcia Ângela (orgs.). A BNCC na contramão do PNE 2014-2014: avaliação e perspectivas. Recife: ANPAE, 2018, p. 55-59.

OLIVEIRA, Inês Barbosa; SUSSEKIND, Maria Luiza. Dimensões político-epistemológicas do equívoco /conservador na educação: A base curricular brasileira no contexto dos currículos nacionais. Revista Portuguesa de Educação, n. 31, 2018, p. 55-74.

OLIVEIRA, Inês Barbosa. Contribuições de Boaventura de Sousa Santos para a reflexão curricular: princípios emancipatórios e currículos pensadospraticados. Revista e-curriculum, São Paulo, v. 8, n. 2, 2013, p. 1-19.

PALANCH, Wagner Barbosa de Lima. Mapeamento de pesquisas sobre currículos de Matemática na Educação Básica brasileira (1987 a 2012). 2016. 283f. Tese (Doutorado em Educação Matemática) - Faculdade de Ciências Exatas e Tecnológicas, Pontifícia Universidade Católica de São Paulo, São Paulo, 2016. 
PASSOS, Carmen Lucia Brancaglion Passos. Parecer sobre o documento da Base Nacional Comum Curricular. Disponível em: http://basenacionalcomum.mec.gov.br/images/relatoriosanaliticos/Carmen_Lucia_Brancaglion_Passos.pdf. acesso 05 Abril 2021.

PEREIRA, Rafael Ferreira de Souza Mendes. Das perguntas wittgensteinianas à pedagogia das competências: ou desmontando a caixa-preta de Perrenoud. Educ. Pesqui., São Paulo, v. 41, n. 1, p. 229- 242, 2015.

PINTO, Antonio Henrique. A Base Nacional Comum Curricular e o Ensino de Matemática: flexibilização ou engessamento do currículo escolar. Bolema, Rio Claro, v. 31, n. 59, p. 1045-1060, 2017.

PIRES, Célia Maria Carolino. Currículos de matemática: para onde se orientam? Revista de Educação PUC-Campinas, Campinas, v. 18, p. 25-34, 2005.

PIRES, Célia Maria Carolino. Educação Matemática e sua Influência no Processo de Organização e Desenvolvimento Curricular no Brasil. Bolema, Rio Claro, v. 21, n. 29, p. 13-42, 2008.

PIRES, Célia Maria Carolino; SILVA, Márcio Antonio. Desenvolvimento curricular em Matemática no Brasil: trajetórias e desafios. Quadrante, Lisboa, v. XX, n. 2, 2011, p. 57-81.

SANTOS, Boaventura de Sousa. Para um novo senso comum: a ciência, o direito e a política na transição paradigmática. São Paulo: Cortez, 2002.

SANTOS, Boaventura de Sousa. A gramática do tempo: para uma nova cultura política. São Paulo: Cortez, 2006.

SANTOS, Boaventura de Sousa. Renovar a teoria crítica e reinventar a emancipação social. São Paulo: Boitempo, 2007.

SANTOS, Boaventura de Sousa. A cruel pedagogia do vírus. Coimbra: Almedina, 2020.

SANTOS, Maria José Costa. O currículo de matemática dos anos iniciais do ensino fundamental na base nacional comum curricular (BNCC): os subalternos falam? Horizontes, Itatiba, v. 36, n. 1, p. 132-143, jan./abr. 2018

SAUL, Ana Maria. A construção do currículo na teoria e prática de Paulo Freire. In: APPLE, Michael; NÓVOA, Antonio. (Orgs.). Paulo Freire: política e pedagogia. Porto: Porto Editora, 1998, p. 151-166.

SILVA, Tomaz Tadeu da. Documentos de identidade: uma introdução às teorias do currículo. Belo Horizonte: Autêntica, 2011.

VALLE, Júlio César Augusto. Os currículos brasileiros e suas políticas sob as perspectivas socioculturais da Educação Matemática: das prescrições aos currículos pensadospraticados. Revista Educon, v. 1, n. 1, pp. 1-17, 2019.

VALLE, Júlio César Augusto. As associações científicas da educação e a Base Nacional Comum Curricular no contexto de sequestro da democracia brasileira. Currículo sem Fronteiras, v. 20, n. 3, p. 919-949, 2020. 
VALLE, Júlio César Augusto; MORAIS, Deise Nancy. Paradoxos aparentes sobre a docência: discursos em torno da Base Nacional Comum Curricular. In: VII Congresso Brasileiro de Educação. Anais ... Bauru, 2019. 